\title{
Microfitoplâncton de águas costeiras amazônicas: Ilha Canela (Bragança, PA, Brasil)
}

\author{
Eliane Brabo de Sousa ${ }^{1,3}$, Vanessa Bandeira da $\operatorname{Costa}^{1}$, Luci Carneiro Cajueiro Pereira ${ }^{2}$ e \\ Rauquírio Marinho da Costa ${ }^{1}$
}

Recebido em 23/04/2007. Aceito em 4/09/2007

\begin{abstract}
RESUMO - (Microfitoplâncton de águas costeiras amazônicas: Ilha Canela (Bragança, PA, Brasil)). Variações sazonal e nictemeral do microfitoplâncton foram estudadas em uma estação fixa ( $00^{\circ} 46^{\prime} 37,2$ ' 'S-04643'24,5' 'W), localizada em uma área costeira próxima à ilha Canela (Norte do Brasil), durante os meses de setembro e dezembro/2004 (período seco) e março e junho/2005 (período chuvoso). As amostras destinadas à análise qualitativa do fitoplâncton foram obtidas a partir da filtragem de $400 \mathrm{~L}$ de água, através de uma rede planctônica ( $65 \mu \mathrm{m}$ de abertura de malha), durante marés de sizígia, em intervalos regulares de três horas, por um período de 24 horas. $\mathrm{O}$ material coletado foi fixado com formol neutro a 4\%. Paralelamente a essas coletas foi medida a salinidade da superfície da água. A salinidade apresentou variação significativa ao longo do período de estudo, variando entre 26,1 (junho/2005) e 39,0 (dezembro/2004), caracterizando o ambiente como eualino-polialino. Foram identificados 130 táxons incluídos nas divisões Cyanophyta (dois táxons), Bacillariophyta (115 táxons) e Dinophyta (13 táxons). As diatomáceas dominaram o microfitoplâncton da área, sendo Asterionellopsis glacialis, Dimeregramma minor, Skeletonema sp. e Thalassiosira subtilis os táxons mais frequientes e abundantes. Os altos valores de salinidade condicionaram a maior representatividade das espécies marinhas neríticas, polialóbias. Os processos de ressuspensão provocados pelos ventos e arrebentação das ondas promoveram intercâmbios entre as populações planctônicas e ticoplanctônicas, dentre as quais as espécies Dimeregramma minor, Triceratium biquadratum e T. pentacrinus representaram novas ocorrências para as águas costeiras do litoral amazônico.
\end{abstract}

Palavras-chave: fitoplâncton, composição, Ilha Canela, costa amazônica

ABSTRACT - (Microphytoplankton of Amazon coastal waters: Canela Island (Bragança, Pará State, Brazil)). Seasonal and nyctemeral variations of the microphytoplankton were studied at a fixed station (0046'37.2'S- $046^{\circ} 43$ '24.5' W) on Canela Island (North Brazil) in September and December/2004 (dry season) and in March and June/2005 (rainy season). Samples for qualitative phytoplankton studies were obtained by filtering $400 \mathrm{~L}$ of surface water in the surf zone of the island through plankton nets $(65 \mu \mathrm{m}$ mesh size). Field work was carried out during spring tides and samples were collected every 3 hours during a 24-hour period. The collected material was fixed in neutral formaldehyde at $4 \%$. Simultaneously, salinity of the water surface was also measured. Salinity showed significant variation throughout the study period, ranging from 26.1 (June/2005) to 39.0 (December/2004), characterizing the environment as euhalinepolyhaline. A total of 130 taxa were identified, belonging to Cyanophyta (two taxa), Bacillariophyta (115 taxa) and Dinophyta (13 taxa). Diatoms were the dominant group of microphytoplankton at Canela Island. Asterionellopsis glacialis, Dimeregramma minor, Skeletonema sp. and Thalassiosira subtilis were the most frequent and abundant taxa. High salinities favored the occurrence of polyhalobous neritic marine species. Resuspension processes caused by wind and wave surf zone were responsible for exchange between planktonic and ticoplanktonic populations, including species such as Dimeregramma minor, Triceratium biquadratum and T. pentacrinus which represented new occurrences for the Amazon coast.

Key words: Phytoplankton, composition, Canela Island, Amazon coast

\section{Introdução}

A Zona Costeira Amazônica brasileira representa cerca de $35 \%$ da costa do País, estendendo-se por mais de $2.500 \mathrm{~km}$, desde a foz do Rio Oiapoque, no Amapá, até a Baía de São Marcus, no Maranhão (Isaac \& Barthem
1995). Toda a linha costeira do Norte do Brasil é dominada por macromarés e apresenta feições geomorfológicas características, com extensos depósitos de planície de maré, estuários, manguezais, baixios, pântanos salinos, dunas, praias e leques de lavagens associados (Souza Filho \& El-Robrini 1996).

\footnotetext{
1 Universidade Federal do Pará, Departamento de Biologia, Laboratório de Plâncton e Cultivo de Microalgas, Campus Universitário de Bragança, Rua Leandro Ribeiro s.n., Bairro da Aldeia, 68600-000 Bragança, PA, Brasil

2 Universidade Federal do Pará, Laboratório de Oceanografia Costeira, Campus Universitário de Bragança, Rua Leandro Ribeiro s.n., Bairro da Aldeia, 68600-000 Bragança, PA, Brasil

3 Autor para correspondência: elianebrabos@hotmail.com
} 
Nesta região estão localizados cerca de $85 \%$ dos manguezais do País (Lara 2003), dos quais estima-se que uma área de 1,38 milhões de hectares pertença ao litoral Paraense (Kjerfve \& Lacerda 1993), o qual se encontra no centro de grandes sistemas de circulação atmosférica e oceânica equatorial que, juntamente com a descarga hídrica e sedimentar do rio Amazonas, exercem uma influência direta na dinâmica costeira atual.

Embora a costa amazônica apresente características hidrodinâmicas e climatológicas únicas no Brasil e represente uma das áreas prioritárias para o reconhecimento e conservação da biodiversidade de ecossistemas costeiros, poucas são as informações referentes às comunidades fitoplanctônicas locais, as quais se concentram em estudos realizados na plataforma continental sob a influência da pluma Amazônica (MüllerMelchers 1957; Vannucci \& Queiroz 1963; Wood 1966; Teixeira \& Tundisi 1967; Smith \& Demaster 1996) e em menor escala, nos ambientes estuarinos dos estados do Pará (Simith et al. 2002; Soares \& Paiva 2002; Melo et al. 2006) e Maranhão (Almeida et al. 2004).

As comunidades fitoplanctônicas em função de sua importância nas redes tróficas aquáticas, de seu caráter dinâmico e das rápidas respostas às alterações físicas e químicas do meio aquático, são de extrema importância para a caracterização ecológica de ambientes costeiros, uma vez que estas comunidades estabelecem complexas relações intra e interespecíficas na competição e utilização do espaço e dos recursos disponíveis na coluna d'água (Valiela 1995).

Visando compreender a estrutura e a dinâmica planctônica da Zona Costeira Amazônica, este trabalho teve por objetivo caracterizar a variação sazonal e nictemeral do microfitoplâncton, em termos de composição, enquadramento ecológico, freqüência de ocorrência e abundância relativa das espécies de águas costeiras adjacentes a uma ilha costeira amazônica, ilha Canela, Bragança (PA). Este trabalho constitui o primeiro registro sobre o plâncton nesta área, a qual é considerada Área de Proteção Ambiental (APA).

\section{Material e métodos}

Área de estudo - A ilha Canela $\left(00^{\circ} 46^{\prime} 45^{\prime \prime}-00^{\circ} 47^{\prime} 06^{\prime \prime} \mathrm{S}\right.$ e $46^{\circ} 41^{\prime} 02^{\prime \prime}-46^{\circ} 43^{\prime} 04^{\prime \prime}$ 'W) é uma pequena ilha litorânea com cerca de $5 \mathrm{~km}^{2}$ de extensão pertencente ao município de Bragança do qual dista $30 \mathrm{~km}$ em linha reta e $10 \mathrm{~km}$ da sua costa, sendo banhada por águas atlânticas e pela bacia vertente do rio Taperaçú (Fig. 1).

Encontra-se inserida na Planície Costeira Bragantina, Nordeste do Estado do Pará, a qual abrange a faixa costeira do município de Bragança, região que se estende da ponta do Maiaú até a foz do rio Caeté $\left(00^{\circ} 46^{\prime} 00^{\prime}\right.$ - $1^{\circ} 00^{\prime} 00^{\prime \prime}$ S e $\left.46^{\circ} 36^{\prime} 00^{\prime \prime}-46^{\circ} 44^{\prime} 00^{\prime \prime} \mathrm{W}\right)$, perfazendo uma área de aproximadamente $1.570 \mathrm{~km}^{2}$ (Souza Filho \& El-Robrini 1996).

O clima da região é úmido, megatérmico com temperaturas médias do ar superior a $25^{\circ} \mathrm{C}$ e precipitação anual de $2.500 \mathrm{~mm}$ a $3.000 \mathrm{~mm}$ (Martorano et al. 1993), com um período seco de agosto a dezembro e uma estação chuvosa de janeiro a julho, que representa mais 90\% da precipitação total anual (Moraes et al. 2005).

A ilha Canela é cercada por uma área de superfícies arenosa e lamosa-arenosa, as quais são influenciadas pelas marés. Sua vegetação é predominantemente formada pela floresta de mangue jovem, com o domínio da espécie Rhizophora mangle Linneus, abrigando inúmeras espécies de aves marinhas e funcionando como local de descanso e reprodução para uma numerosa população de guarás (Eudocimus ruber Linnaeus) o que a fez ser considerada uma Área de Proteção Ambiental (Schories \& Gorayeb 2001).

Coleta e análise de dados - Os dados de precipitação pluviométrica foram obtidos na estação pluviométrica de Tracuateua/PA $\left(01^{\circ} 04^{\prime}\right.$ S $\left.-46^{\circ} 54^{\prime} \mathrm{W}\right)$ e cedidos pelo Instituto Nacional de Meteorologia do Pará (INMET-PA).

Os dados de vento foram obtidos em uma estação meteorológica da Universidade Federal do Pará (UFPA), situada próximo à praia de Ajuruteua, e cedidos pelo Projeto Experimento de Grande Escala da BiosferaAtmosfera da Amazônia (LBA).

Em uma estação fixa $\left(00^{\circ} 46^{\prime} 37,2\right.$ ' $S$ $046^{\circ} 43^{\prime} 24,5^{\prime \prime} \mathrm{W}$ ) localizada na praia da ilha Canela foram realizadas coletas do microfitoplâncton e medidas dos

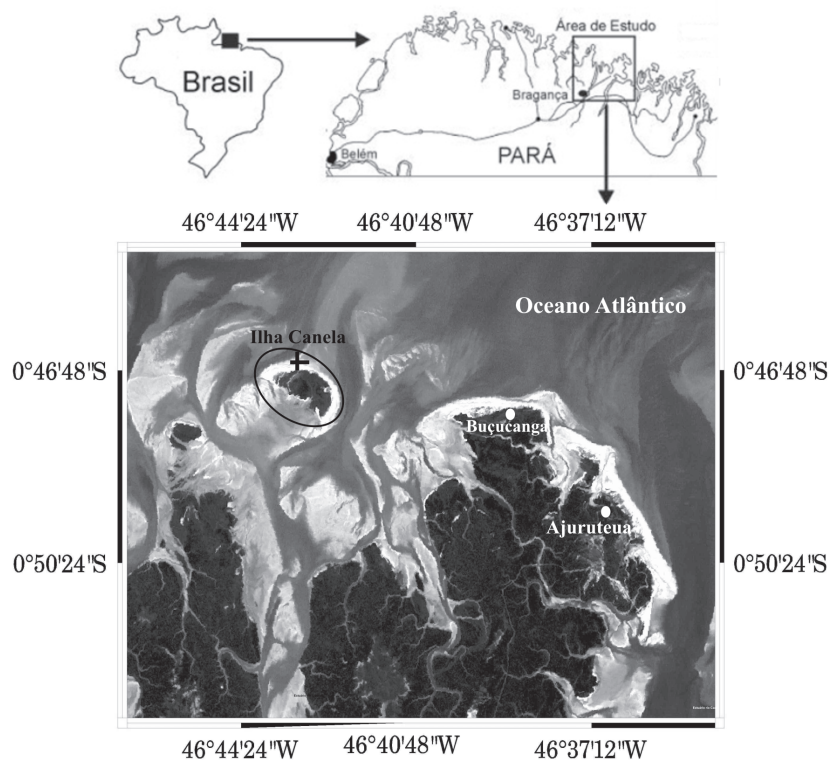

Figura 1. Área de estudo com a localização da estação de coleta (+), ilha Canela, Bragança, PA, Brasil (Imagem TM-Ladsat 5, composição 1R2G3B). 
valores de salinidade da superfície da água durante os períodos seco (setembro e dezembro/2004) e chuvoso (março e junho/2005), em marés de Sizígia de lua nova, a intervalos de três horas, durante um período de 24 horas, compreendendo dois ciclos sucessivos de maré.

Os valores de salinidade foram medidos in situ, na superfície da água, através de uma sonda Multiparâmetro WTW (modelo 340i) e as amostras destinadas ao estudo qualitativo do microfitoplâncton foram obtidas por intermédio de uma rede cônico-cilíndrica de plâncton de $65 \mu \mathrm{m}$ de abertura de malha, através da qual foram filtrados $400 \mathrm{~L}$ de água da camada subsuperficial da zona de arrebentação da praia. O material coletado foi fixado em formol neutro a $4 \%$ e analisado através da montagem de lâminas temporárias observadas sob um microscópio binocular Zeiss (Axioscop 40).

A identificação, a nomenclatura e o enquadramento ecológico dos táxons foram baseados nos trabalhos de Desikachary (1959), Sournia (1986), Valente-Moreira et al. (1987), Moreira Filho et al. (1990), Silva-Cunha \& Eskinazi-Leça (1990), Valente-Moreira et al. (1994), Tomas (1997), Moreira Filho et al. (1999), entre outros.

A identificação dos táxons de diatomáceas foi realizada através da observação de lâminas permanentes montadas segundo Müller-Melchers \& Ferrando (1956) e através de imagens obtidas por intermédio de um Microscópio Eletrônico de Varredura (MEV) LEO, modelo $1450 \mathrm{VP}$.

A ordenação dos táxons baseou-se nos sistema de Round et al. (1990), para as diatomáceas; Steindinger \& Tangen (1997) para os dinoflagelados e Desikachary (1959) para as cianofíceas.

A frequiência de ocorrência dos táxons foi calculada segundo Mateucci \& Colma (1982) utilizando a relação entre o número de amostras, nas quais cada táxon ocorreu, e o número total de amostras analisadas, tendo sido estabelecidas as seguintes categorias: muito frequiente $(\geq 75 \%)$, freqüente $(<75 \%$ e $\geq 50 \%)$, pouco freqüente $(<50 \%$ e $\geq 25 \%)$ e esporádica $(<25 \%)$.

A abundância relativa foi calculada a partir da contagem dos 100 primeiros organismos encontrados em lâminas (Lobo \& Leighton 1986), sendo adotadas as seguintes categorias: dominante $(>70 \%)$, abundante $(\leq 70 \%$ e $>40 \%)$, pouco abundante $(\leq 40 \%$ e $>10 \%)$ e rara $(\leq 10 \%)$.

A análise de variância (ANOVA-fator único) foi aplicada para comparar os valores de salinidade entre os diferentes períodos sazonais, meses e ciclo nictemeral estudados. Para identificar diferenças significativas $(\mathrm{p}<0,05)$ existentes entre os tratamentos da ANOVA foi realizado um teste a posteriori de Tukey HDS (Honestly Significantly Different). Para estas análises foi utilizado o programa Statistica ${ }^{\circledR}$ versão 6.0.

\section{Resultados}

Os índices pluviométricos mensais registrados nos últimos 10 anos apresentaram médias que oscilaram entre 4,0 mm, no mês de novembro, e 506,7 mm, no mês de março, demonstrando a ampla variação dos valores de precipitação ao longo do ciclo anual. Nos meses de coleta estes índices foram de $8,9 \mathrm{~mm}, 50,4 \mathrm{~mm}, 501,6 \mathrm{~mm}$ e $188,1 \mathrm{~mm}$, nos meses de setembro/2004, dezembro/2004, março/2005 e junho/2005, respectivamente (Fig. 2). O total anual registrado para o ano de 2004 foi 17,4\% (768,7 mm) superior ao observado em 2005.

Os ventos sopraram com maior intensidade no período seco, com velocidades médias mensais variando entre 3,3 e 3,9 m.s ${ }^{-1}$, respectivamente, nos meses de agosto/2004 e outubro/2004. Os ventos mais fortes foram registrados nos meses de setembro/2004 e outubro/2004 com 3,8 e 3,9 m.s. ${ }^{-1}$, respectivamente. Durante o período chuvoso, a velocidade dos ventos variou entre 1,8 e 3,0 m.s. ${ }^{-1}$ nos meses de maio/2005 e janeiro/2005, respectivamente. Os ventos de Nordeste (NE) predominam na maior parte do ano, exceto nos meses de maio/2005 a julho/2005, quando predominaram os ventos de Sudeste (SE). Durante o período chuvoso foi possível observar também ventos provenientes de Sudoeste (SW) e Noroeste (NW) (Fig. 3).

A salinidade na área estudada apresentou valores que oscilaram entre 26,1 (junho/2005, às 5:30 h) e 39,0 (dezembro/2004, às 17:30 h e 20:30 h), sendo observadas diferenças significativas $(\mathrm{F}=43,182 ; \mathrm{p}=0,0001)$ entre os períodos sazonais estudados, com valores significativamente mais elevados em dezembro/2004 e menos elevados em junho/2005. (Fig. 4). Em relação ao

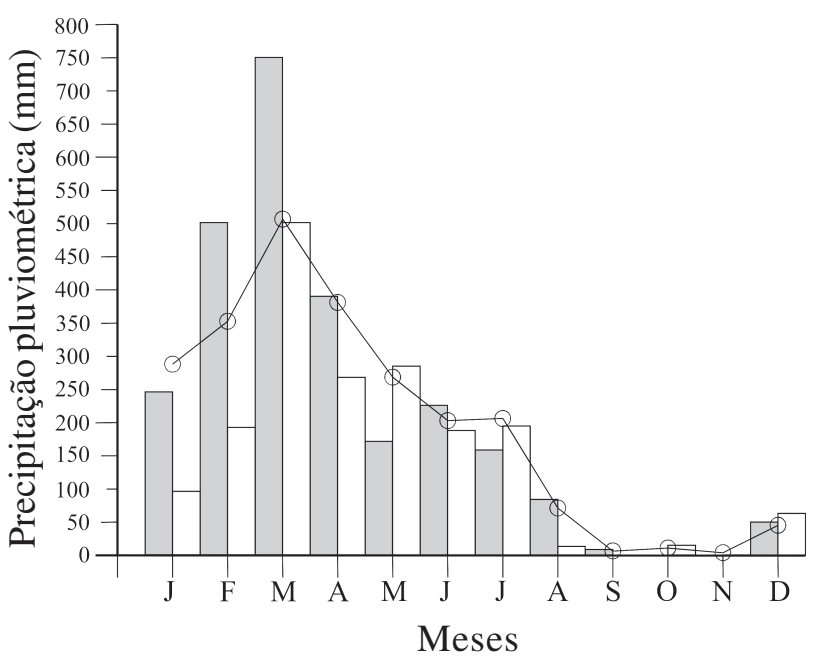

Figura 2. Precipitação total (mm) referente aos anos de estudo (2004 e 2005) e médias da precipitação mensal histórica dos últimos 10 anos (1996 a 2005) (Fonte: INMET, Estação de Tracuateua, PA, Brasil, 0104'S-4654'W a $36 \mathrm{~m})$. ( $\square=2004 ; \square=2005$; $-\mathrm{O}-=$ Média histórica (1996-2005)). 


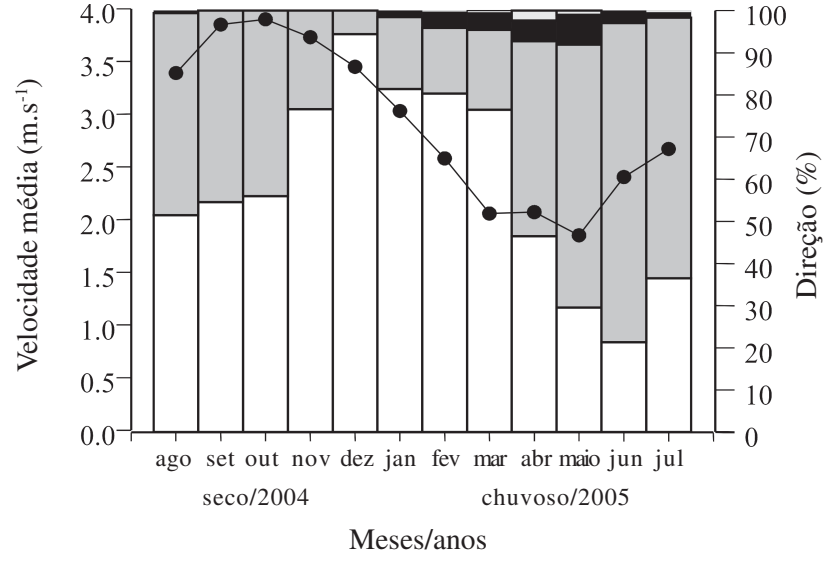

Figura 3. Velocidade média mensal $\left(\mathrm{m} . \mathrm{s}^{-1}\right)$ e direção dos ventos referentes aos períodos seco/2004 e chuvoso/2005, registrados na Planície Costeira Bragantina (Fonte: LBA, Estação de Ajuruteua, $\mathrm{PA}$, Brasil, $00^{\circ} 43^{\prime} \mathrm{S}-45^{\circ} 55^{\prime} \mathrm{W}$ a $\left.28 \mathrm{~m}\right) .(\square=\mathrm{NE}$; $\square=\mathrm{SE}$; $\boldsymbol{\square}=\mathrm{SW}$; - = NW; $-\bullet-=$ velocidade dos ventos).

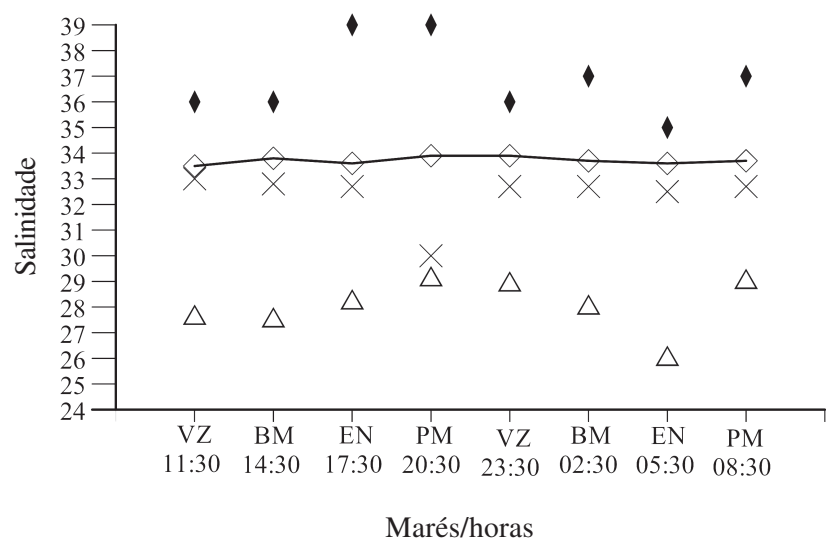

Figura 4. Variação temporal da salinidade da superfície da água na ilha Canela (Bragança, PA, Brasil). (-৩-= setembro/2004, $-\checkmark-=$ sezembro/2004, $-\times-=\operatorname{março} / 2005,-\triangle-=$ junho/2005; VZ - vazante, BM - baixa-mar, EN - enchente, PM - preamar).

ciclo nictemeral não ocorreu variação significativa entre os valores de salinidade $(\mathrm{F}=16,541 \mathrm{p}=0,0621)$.

Microfitoplâcton - O microfitoplâncton esteve representado por 130 táxons pertencentes às divisões Cyanophyta (dois táxons), Dinophyta (13 táxons) e Bacillariophyta (115 táxons), correspondendo a 1,5\%, 10,0\% e 88,5\% do total de táxons, respectivamente.

O maior número de táxons foi registrado em dezembro/2004, com 115 táxons distribuídos entre as divisões: Bacillariophyta (101 táxons), Dinophyta (12 táxons) e Cyanophyta (dois táxons). Em Junho/2005 foi registrado o menor número de táxons, 92 táxons, distribuídos entre as divisões Bacillariophyta (82 táxons), Dinophyta (oito táxons) e Cyanophyta (dois táxons) (Fig. 5).

Durante a estação seca foram registrados 122 táxons, enquanto que na estação chuvosa foram identificados 109 táxons. Em ambos os períodos sazonais, o número de táxons identificados durante o dia $(55,4 \%)$ foi superior ao observado durante a noite $(44,6 \%)$. O menor número de espécies (60 spp.) ocorreu durante o período chuvoso (às 23:30 h) e o maior número (86 spp.) durante o período seco (às 11:30 h) (Fig. 6).

As diatomáceas dominaram o microfitoplâncton em ambos os períodos sazonais, compreendendo três classes, dez sub-classes, 19 ordens, duas sub-ordens, 28 famílias, 47 gêneros, 86 espécies, 26 morfo-espécies e três variedades. Os gêneros predominantes foram Chaetoceros Ehrenberg (21 táxons), Coscinodiscus Ehrenberg (13 táxons), Thalassiosira Cleve (seis táxons) e Odontella Agardh (cinco táxons). As divisões Dinophyta e Cyanophyta constituíram componentes de menor representatividade, apresentando uma classe, quatro ordens, sete famílias, sete gêneros, cinco espécies, seis morfo-espécies e duas variedades de dinoflagelados; uma classe, uma ordem, uma família e duas morfoespécies de cianofíceas (Tab. 1).

Os táxons exclusivos do período seco foram: Biddulphia obtusa, Biddulphia sp., B. tuomey, Cerataulina pelagica, Ceratium tripos var. tripos, Chaetoceros compressus, C. gracilis, C. mitra, C. teres, C. tortissimus, Coscinodiscus granii, Coscinodiscus sp. 2, Eunotia sp., Guinardia cylindrus, Navicula sp. 3, Pleurosigma var. quadrata, Podolampas sp., Prorocentrum sp., Triceratium biquadratum e T. pentacrinus. Estiveram representadas apenas durante o período chuvoso, as espécies: Actinoptychus splendens, Coscinodiscus thorii, Ceratium macroceros, Ditylum sol, Palmeria hardmanniana, Rhizosolenia bergonii e Terpsinoe musica.

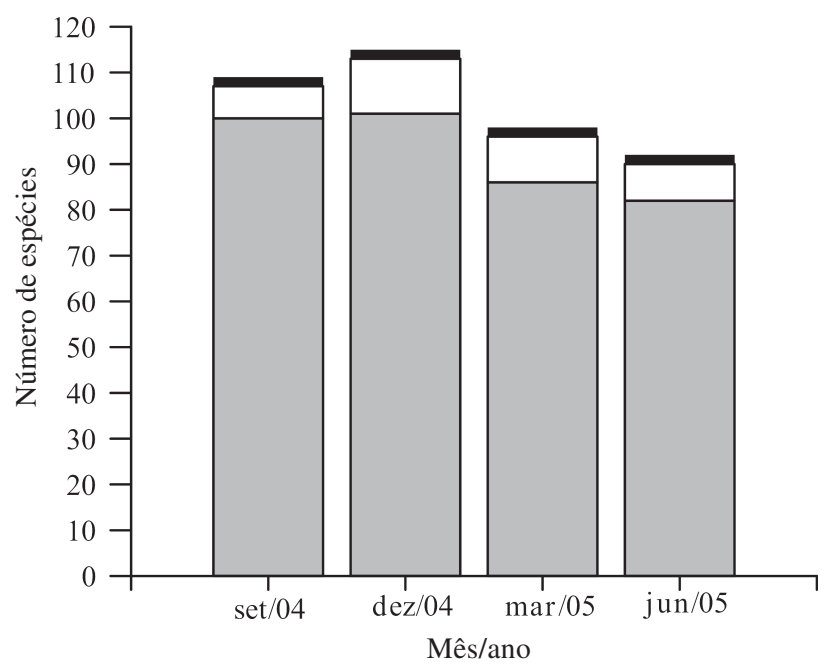

Figura 5. Variação mensal do microfitoplâncton identificado na ilha Canela (Bragança, PA, Brasil). ( $\square=$ Bacillariophyta; $\square=$ Dinophyta; - = Cyanophyta). 

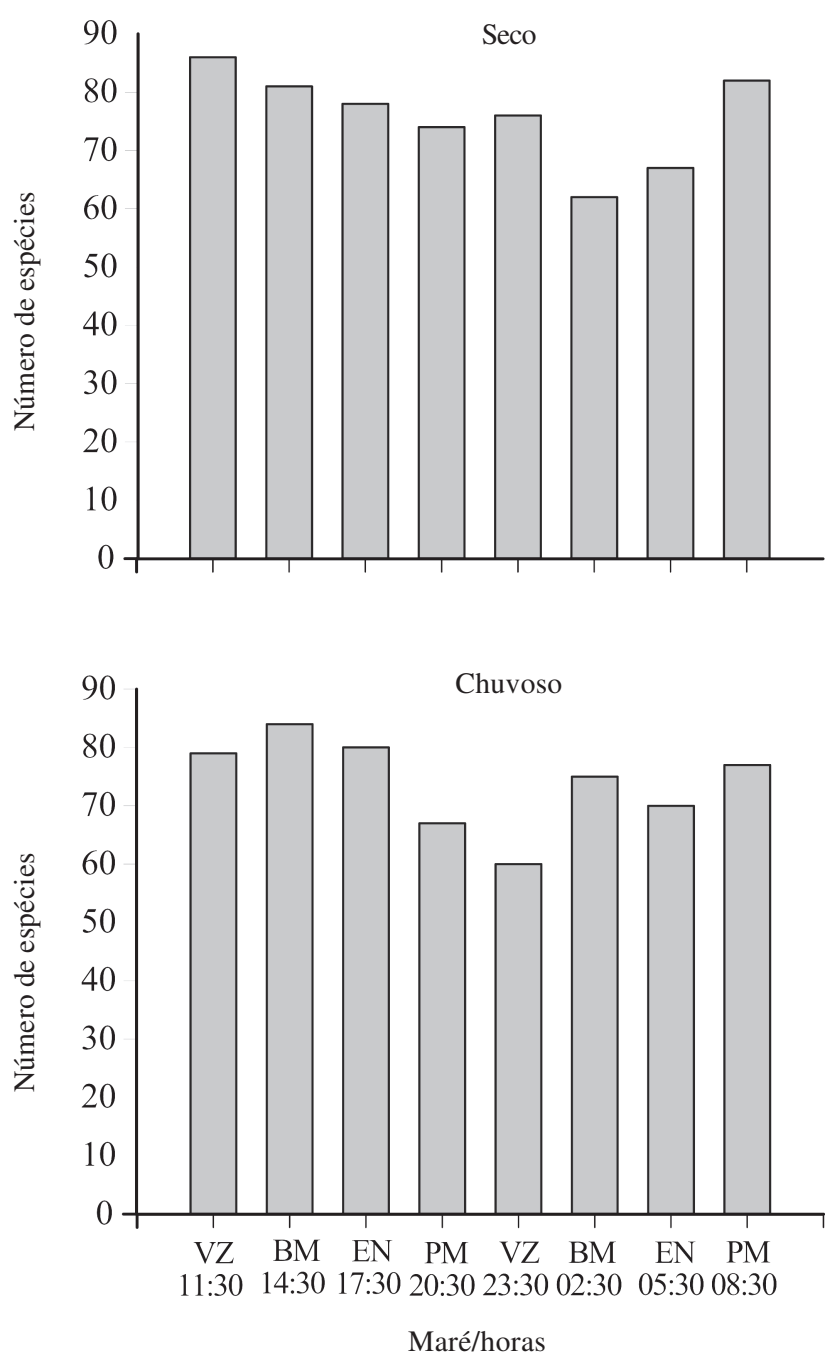

Figura 6. Variações sazonal e nictemeral do microfitoplâncton identificado na ilha Canela (Bragança, PA, Brasil): seco (setembro e dezembro/2004); chuvoso (março e junho/2005). (VZ - vazante, BM - baixa-mar, EN - enchente, PM - preamar).

A maioria das espécies identificadas ocorreu de maneira esporádica $(36,9 \%)$, seguida pelas espécies muito freqüentes $(27,7 \%)$, pouco freqüentes $(20,8 \%)$ e freqüentes (14,6\%). As espécies Asterionellopsis glacialis, Campylosira cymbelliformis, Dimeregramma minor, Ditylum brightwellii, Odontella regia, Skeletonema sp., Thalassionema frauenfeldii e Thalassiosira subtilis estiveram presentes em $100 \%$ das amostras (Tab. 1).

Do total dos táxons identificados, $75 \%$ constituem espécies marinhas planctônicas e 25\% marinhas litorais. Entre as espécies marinhas planctônicas $47,2 \%$ são neríticas, 32,0\% oceânicas e 20,8\% neríto-oceânicas. As espécies ticoplanctônicas representaram $20,0 \%$ da flora. Com relação à tolerância às variações de salinidade, $12,5 \%$ são espécies eurialinas, $30,2 \%$ polialóbias e $6,3 \%$ mesoalóbias. As demais espécies (51,0\%) não apresentaram categorias ecológicas definidas em função deste parâmetro.

As espécies abundantes e pouco abundantes durante os períodos estudados foram: Asterionellopsis glacialis, Dimeregramma minor, Skeletonema sp. e Thalassiosira subtilis, com porcentagens oscilando entre $4 \%$ (março/2005, baixa-mar das 14:30 h) e 34\% (junho/2005, preamar das 20:30 h); 6\% (junho/2005, enchente das $17: 30 \mathrm{~h}$ ) e $21 \%$ (junho/2005, preamar das $8: 30 \mathrm{~h}$ ); $6 \%$ (junho/2005, vazante das 23:30 h) e 49\% (setembro/2004, preamar das $8: 30 \mathrm{~h}$ ); e $2 \%$ (março/2005, baixa-mar das $14: 30 \mathrm{~h}$ ) e $22 \%$ (junho/2005, baixa-mar das $2: 30 \mathrm{~h}$ ), respectivamente (Fig. 7).

\section{Discussão}

Variações no regime meteorológico, nas características geomorfológicas regionais e os impactos antropogênicos nas áreas costeiras, estabelecem, em conjunto, o regime hidrográfico particular de cada região e, conseqüentemente, as características taxonômicas e a dinâmica temporal das comunidades planctônicas locais (Brandini et al. 1997).

A precipitação pluviométrica, durante os meses do presente estudo, alcançou índices semelhantes aos registrados nos últimos dez anos, com um período sazonal bem definido, com mais de $94 \%$ das chuvas ocorrendo nos meses de janeiro a julho, como observado por Moraes et al. (2005) para a zona costeira bragantina.

Os valores de salinidade mostraram variações altamente significativas entre os períodos sazonais estudados, observando-se uma redução em função do aumento da precipitação pluviométrica, o que caracterizou o ambiente como eualino, no período seco, e eualino a polialino, durante o período chuvoso (Sistema de Veneza 1958). Este padrão sazonal da salinidade é característico de ambientes costeiros do Nordeste paraense (Magalhães et al. 2006).

$\mathrm{O}$ registro de altos valores de salinidade durante o mês de dezembro sugere a influência dos ventos intensos de Nordeste que atuam sobre as águas superficiais desta área durante este período (velocidade média $=3,5 \mathrm{~m} \cdot \mathrm{s}^{-1}$ ), provocando altas taxas de evaporação. Também se observa a presença de pequenos canais rasos de marés, os quais, possivelmente represam águas salinas que se misturam às águas da praia, principalmente, durante a enchente e a preamar. Por outro lado, o mês de dezembro é precedido pelos meses mais secos da região (setembro, outubro e novembro), que juntos somam menos que $20 \mathrm{~mm}$ de precipitação pluviométrica, menos de $6 \%$ do total anual (Moraes et al. 2005).

As diatomáceas dominaram o microfitoplâncton na área estudada, onde as espécies Dimeregramma minor, 
Tabela 1. Composição e classificação ecológica do microfitoplâncton da ilha Canela (Bragança, Pará, Brasil), durante o período seco (setembro e dezembro/2004) e chuvoso (março e junho/2005). Legenda: Sec = período seco; Chu = período chuvoso; *nova ocorrência; M.L = marinha litoral; M.P.N = marinha planctônica nerítica; M.P.O = marinha planctônica oceânica; M.P.N-O = marinha planctônica neríto-oceânica; Tc = ticoplanctônica; Eu = eurialina; Me; Mesoalóbia; Po = Polialóbia .

\begin{tabular}{|c|c|c|c|c|c|c|c|}
\hline \multirow[t]{2}{*}{ Táxon } & \multicolumn{2}{|c|}{ Estações } & \multirow[t]{2}{*}{ Ecologia } & \multirow[t]{2}{*}{ Táxon } & \multicolumn{2}{|c|}{ Estações } & \multirow[t]{2}{*}{ Ecologia } \\
\hline & $\mathrm{Sec}$ & Chu & & & $\mathrm{Sec}$ & Chu & \\
\hline CYANOPHYTA & & & & Terpsinoe musica Ehrenberg & & $\mathrm{X}$ & M.L, Me \\
\hline CYANOPHYCEAE & & & & TRICERATIALES & & & \\
\hline OSCILLATORIALES & & & & TRICERATIACEAE & & & \\
\hline OSCILLATORIACEAE & & & & Auliscus sp. & $\mathrm{X}$ & $\mathrm{X}$ & \\
\hline Oscillatoria $\mathrm{sp.} 1$ & $\mathrm{X}$ & $X$ & & Cerataulus smithii (Roper) Ralfs & $X$ & $\mathrm{X}$ & M.L, Tc, Eu \\
\hline Oscillatoria sp. 2 & $X$ & $\mathrm{X}$ & & Eupodiscus radiatus Bailey & $\mathrm{X}$ & $X$ & M.L, Tc \\
\hline BACILLARIOPHYTA & & & & Odontella aurita (Lyhgbye) & $\mathrm{X}$ & $\mathrm{X}$ & M.L, Tc \\
\hline COSCINODISCOPHYCEAE & & & & C. A. Agardh & & & \\
\hline THALASSIOSIROPHYCIDAE & & & & O. longicruris (Greville) Hoban & $X$ & $\mathrm{X}$ & M.P.N, Po \\
\hline THALASSIOSIRALES & & & & O. mobiliensis (Bailey) Grunow & $\mathrm{X}$ & $\mathrm{X}$ & M.P.N-O, Po \\
\hline THALASSIOSIRACEAE & & & & O. regia (Ostenfeld) Simonsen & $\mathrm{X}$ & $\mathrm{X}$ & M.P.N \\
\hline Thalassiosira eccentrica & $\mathrm{X}$ & $\mathrm{X}$ & M.L, Tc, Eu & O. sinensis (Greville) Grunow & $X$ & $\mathrm{X}$ & M.P.N-O \\
\hline (Ehrenberg) Cleve & & & & Pleurosira laevis var. laevis & $\mathrm{X}$ & $\mathrm{X}$ & M.L, Tc, Eu \\
\hline T. leptopus (Grunow) Hasle e & $\mathrm{X}$ & $\mathrm{X}$ & M.P.N-O & Ehrenberg & & & \\
\hline Fryxell & & & & Triceratium biquadratum Jan* & $\mathrm{X}$ & & M.L, Tc \\
\hline Thalassiosira subtilis & $\mathrm{X}$ & $\mathrm{X}$ & M.P.O & T. favus (Ehrenberg) Wallich & $\mathrm{X}$ & $\mathrm{X}$ & M.L, Tc, Eu \\
\hline (Ostenfeld) Gran & & & & T. pentacrinus (Ehrenberg) & $\mathrm{X}$ & & M.L \\
\hline Thalassiosira sp. 1 & $\mathrm{X}$ & $X$ & & Wallich* & & & \\
\hline Thalassiosira sp. 2 & $X$ & $X$ & & Triceratium sp. & $\mathrm{X}$ & $\mathrm{X}$ & \\
\hline Thalassiosira sp. 3 & $\mathrm{X}$ & $\mathrm{X}$ & & PLAGIOGRAMMACEAE & & & \\
\hline LAUDERIACEAE & & & & Dimeregramma minor (Gregory) & $X$ & $\mathrm{X}$ & M. L, Tc, Po \\
\hline Lauderia annulata Cleve & $\mathrm{X}$ & $X$ & M.P.N & Ralfs* & & & \\
\hline SKELETONEMATACEAE & & & & Plagiogramma sp. & $\mathrm{X}$ & $\mathrm{X}$ & \\
\hline Skeletonema sp. & $\mathrm{X}$ & $X$ & & HEMIAULALES & & & \\
\hline COSCINODISCOPHYCIDAE & & & & HEMIAULACEAE & & & \\
\hline MELOSIRALES & & & & Cerataulina pelagica (Cleve) & $\mathrm{X}$ & & M.P.O, Po \\
\hline MELOSIRACEAE & & & & Hendey & & & \\
\hline Melosira moniliformis & $\mathrm{X}$ & $\mathrm{X}$ & M.L, Tc, Me & Hemiaulus heibergii Cleve & $\mathrm{X}$ & $\mathrm{X}$ & M.P.N \\
\hline C.A. Agardh & & & & H. membranaceus Cleve & $\mathrm{X}$ & $\mathrm{X}$ & M.P.N \\
\hline PARALIALES & & & & H. sinensis Greville & $\mathrm{X}$ & $X$ & M.P.N, Po \\
\hline PARALIACEAE & & & & BELLEROCHEACEAE & & & \\
\hline $\begin{array}{l}\text { Paralia sulcata (Ehrenberg) Cleve } \\
\text { COSCINODISCALES }\end{array}$ & $\mathrm{X}$ & $\mathrm{X}$ & M.L, Tc, Eu & $\begin{array}{l}\text { Bellerochea horologicalis } \\
\text { von Stosch }\end{array}$ & $\mathrm{X}$ & $\mathrm{X}$ & M.P.N \\
\hline COSCINODISCACEAE & & & & B. malleus (Brightwell) & $\mathrm{X}$ & $\mathrm{X}$ & M.P.N \\
\hline Coscinodiscus apiculatus Ehrenberg & $\mathrm{X}$ & $\mathrm{X}$ & M.P.O & van Heurck & & & \\
\hline C. argus Ehrenberg & $\mathrm{X}$ & $\mathrm{X}$ & M.P.N & STREPTOTHECACEAE & & & \\
\hline C. centralis Ehrenberg & $\mathrm{X}$ & $\mathrm{X}$ & M.P.N-O & Helicotheca tamesis (Shrubsole) & $X$ & $X$ & M.P.N \\
\hline C. concinnus Wm. Smith & $\mathrm{X}$ & $\mathrm{X}$ & M.P.N & Ricard & & & \\
\hline C. granii Gough & $X$ & & M.P.N, Po & LITHODESMIOPHYCIDAE & & & \\
\hline C. jonesianus (Greville) Ostenfeld & $\mathrm{X}$ & $\mathrm{X}$ & M.P.N, Po & LITHODESMIALES & & & \\
\hline C. jonesianus var. commutata & $\mathrm{X}$ & $\mathrm{X}$ & M.P.N & LITHODESMIACEAE & & & \\
\hline (Grunow) Hustedt & & & & Ditylum brightwellii (West) & $\mathrm{X}$ & $X$ & M.P.N, Po \\
\hline C. obscurus Schmidt & $\mathrm{X}$ & $\mathrm{X}$ & M.P.O & Grunow & & & \\
\hline C. oculus iridis Ehrenberg & $\mathrm{X}$ & $\mathrm{X}$ & M.P.N-O, Po & D. sol Grunow in van Heurck & & $\mathrm{X}$ & M.P.N \\
\hline C. perforatus Ehrenberg & $\mathrm{X}$ & $\mathrm{X}$ & M.P.N-O, Po & Lithodesmium sp. & $\mathrm{X}$ & $\mathrm{X}$ & \\
\hline C. thorii Pavillard & & $X$ & M.P.N, Eu & CYMATOSIROPHYCIDAE & & & \\
\hline Coscinodiscus sp. 1 & $\mathrm{X}$ & $\mathrm{X}$ & & CYMATOSIRALES & & & \\
\hline Coscinodiscus sp. 2 & $\mathrm{X}$ & & & CYMATOSIRACEAE & & & \\
\hline Palmeria hardmanniana Greville & & $\mathrm{X}$ & M.P.N & Campylosira cymbelliformis & $\mathrm{X}$ & $\mathrm{X}$ & M.L, Tc \\
\hline HELIOPELTACEAE & & & & Grunow & & & \\
\hline Actinoptychus senarius (Ehenb.) & $\mathrm{X}$ & $\mathrm{X}$ & M.L, Tc, Me & RHIZOSOLENIOPHYCIDAE & & & \\
\hline Ehrenberg & & & & RHIZOSOLENIALES & & & \\
\hline A. splendens (Shadbolt) Ralfs & & $\mathrm{X}$ & M.L, Tc, Po & RHIZOSOLENIACEAE & & & \\
\hline BIDDULPHIOPHYCIDAE & & & & Guinardia cylindrus (Cleve) Hasle & $X$ & & M.P.O \\
\hline BIDDULPHIALES & & & & G. delicatula (Cleve) Hasle & $\mathrm{X}$ & $\mathrm{X}$ & M.P.N \\
\hline BIDDULPHIACEAE & & & & G. flaccida (Castracane) & $\mathrm{X}$ & $\mathrm{X}$ & M.P.N, Me \\
\hline Biddulphia obtusa Ralfs & $\mathrm{X}$ & & M.L, Tc & H. Peragallo & & & \\
\hline B. tuomeyi (Bailey) Roper & $\mathrm{X}$ & & M.L, Tc & G. striata (Stolterfoth) Hasle & $X$ & $X$ & M.P.O \\
\hline Biddulphia sp. & $\mathrm{X}$ & & & & & & continua \\
\hline
\end{tabular}


Tabela 1 (continuação)

\begin{tabular}{|c|c|c|c|c|c|c|c|}
\hline \multirow[t]{2}{*}{ Táxon } & \multicolumn{2}{|c|}{ Estações } & \multirow[t]{2}{*}{ Ecologia } & \multirow[t]{2}{*}{ Táxon } & \multicolumn{2}{|c|}{ Estações } & \multirow[t]{2}{*}{ Ecologia } \\
\hline & $\mathrm{Sec}$ & Chu & & & $\mathrm{Sec}$ & Chu & \\
\hline $\begin{array}{l}\text { Proboscia alata (Brightwell) } \\
\text { Sundström }\end{array}$ & $\mathrm{X}$ & $\mathrm{X}$ & M.P.O, Po & $\begin{array}{l}\text { Gyrosigma balticum (Ehrenberg) } \\
\text { Rabenhorst }\end{array}$ & $\mathrm{X}$ & $\mathrm{X}$ & M.L, Me \\
\hline Pseudosolenia calcar-avis & $X$ & $X$ & M.P.O, Po & Gyrosigma sp. & $\mathrm{X}$ & $\mathrm{X}$ & \\
\hline (Schultze) Sundström & & & & Pleurosigma angulata & $\mathrm{X}$ & & M.L, Tc \\
\hline Rhizosolenia bergonii H. Perigallo & & $X$ & M.P.O, Po & var. quadrata Smidt & & & \\
\hline R. hebetata (Hensen) Gran & $X$ & $\mathrm{X}$ & M.P.O, Po & Pleurosigma sp. & $\mathrm{X}$ & $\mathrm{X}$ & \\
\hline R. robusta Normam in Pritchard & $X$ & $\mathrm{X}$ & M.P.O, Po & NAVICULACEAE & & & \\
\hline R. setigera Brightwell & $\mathrm{X}$ & $\mathrm{X}$ & M.P.N-O, Po & Meuniera membranacea (Cleve) & $\mathrm{X}$ & $\mathrm{X}$ & M.P.N \\
\hline R. styliformis Brightwell & $X$ & $\mathrm{X}$ & M.P.O, Eu & P.C. Silva & & & \\
\hline CHAETOCEROTOPHYCIDAE & & & & Navicula sp. 1 & $X$ & $X$ & \\
\hline CHAETOCERALES & & & & Navicula sp. 2 & $\mathrm{X}$ & $X$ & \\
\hline CHAETOCERACEAE & & & & Navicula sp. 3 & $\mathrm{X}$ & & \\
\hline Bacteriastrum delicatulum Cleve & $\mathrm{X}$ & $\mathrm{X}$ & M.P.O, Po & BACILLARIALES & & & \\
\hline Bacteriastrum hyalinum Lauder & $X$ & $\mathrm{X}$ & M.P.O, Po & BACILLARIACEAE & & & \\
\hline Bacteriastrum sp. & $X$ & $X$ & & Bacillaria paxillifera & $\mathrm{X}$ & $\mathrm{X}$ & M.L, Tc, Eu \\
\hline Chaetoceros affinis Lauder & $\mathrm{X}$ & $X$ & M.P.N-O, Po & (O.F. Müller) Hendey & & & \\
\hline C. borealis Bailey & $X$ & $X$ & M.P.O, Eu & Cylindrotheca closterium & $\mathrm{X}$ & $\mathrm{X}$ & M.L, Tc, Me \\
\hline C. brevis Shütt & $\mathrm{X}$ & $\mathrm{X}$ & M.P.N-O, Po & (Ehrenberg) Lewin e Reimann & & & \\
\hline C. compressus Lauder & $\mathrm{X}$ & & M.P.N-O, Po & Nitzschia longissima (Brébsson) & $\mathrm{X}$ & $\mathrm{X}$ & M.L, Tc, \\
\hline C. constrictus Gran & $X$ & $X$ & M.P.N & Ralfs & & & \\
\hline C. curvisetus Cleve & $\mathrm{X}$ & $X$ & M.P.N, Po & Pseudo- nitzschia seriata (Cleve) & $\mathrm{X}$ & $\mathrm{X}$ & M.P.N \\
\hline C. debilis Cleve & $X$ & $X$ & M.P.N, Eu & H. Peragallo & & & \\
\hline C. decipiens Cleve & $X$ & $\mathrm{X}$ & M. P.N.-O, Po & Pseudo- nitzshia sp. & $\mathrm{X}$ & $\mathrm{X}$ & \\
\hline C. diadema (Ehrenberg) Gran & $\mathrm{X}$ & $\mathrm{X}$ & M.P.O & RHOPALODIALES & & & \\
\hline C. didymus Ehrenberg & $\mathrm{X}$ & $\mathrm{X}$ & M.P.N-O, Po & RHOPALODIACEAE & & & \\
\hline C. gracilis Shült & $X$ & & M.P.O & Epithemia sp. & $\mathrm{X}$ & $\mathrm{X}$ & \\
\hline C. laciniosus Shütt & $X$ & $X$ & M.P.O & SURIRELLALES & & & \\
\hline C. lorenzianus Grunow & $\mathrm{X}$ & $X$ & M.P.N, Po & ENTOMONEIDACEAE & & & \\
\hline C. mitra (Bailey) Cleve & $X$ & & M.P.O & Entomoneis alata Ehrenberg & $\mathrm{X}$ & $\mathrm{X}$ & M.L, Tc \\
\hline C. peruvianus Brightwell & $\mathrm{X}$ & $\mathrm{X}$ & M.P.O, Po & SURIRELLACEAE & & & \\
\hline C. teres Cleve & $\mathrm{X}$ & & M.P.N & Surirella fastuosa (Ehrenberg) & $X$ & $\mathrm{X}$ & M.L, Tc, Eu \\
\hline C. tortissimus Gran & $X$ & & M.P.N & Kützing & & & \\
\hline Chaetoceros sp. 1 & $X$ & $X$ & & Surirella sp. & $\mathrm{X}$ & $\mathrm{X}$ & \\
\hline Chaetoceros sp. 2 & $\mathrm{X}$ & $X$ & & DINOPHYTA & & & \\
\hline Chaetoceros sp. 3 & $X$ & $X$ & & DINOPHYCEAE & & & \\
\hline Chaetoceros sp. 4 & $X$ & $\mathrm{X}$ & & NOCTILUCALES & & & \\
\hline LEPTOCYLINDRALES & & & & NOCTILUCACEAE & & & \\
\hline LEPTOCYLINDRACEAE & & & & Noctiluca scintillans (Macartney) & $\mathrm{X}$ & $\mathrm{X}$ & M.P.N \\
\hline Leptocilyndrus danicus Cleve & $X$ & $X$ & M.P.N, Po & Kofoid e Swezy & & & \\
\hline L. minimus Gran & $X$ & $\mathrm{X}$ & M.P.N & GONYAULACALES & & & \\
\hline FRAGILARIOPHYCEAE & & & & CERATIACEAE & & & \\
\hline FRAGILARIOPHYCIDAE & & & & Ceratium fusus (Ehrenberg) & $X$ & $\mathrm{X}$ & M.P.N \\
\hline FRAGILARIALES & & & & Dujardin & & & \\
\hline FRAGILLARIACEAE & & & & C. inflatum (Kofoid) Jörgensen & $\mathrm{X}$ & $\mathrm{X}$ & M.P.O \\
\hline $\begin{array}{l}\text { Asterionellopsis glacialis } \\
\text { (Castracane) Round }\end{array}$ & $\mathrm{X}$ & $\mathrm{X}$ & M.P.N, Eu & $\begin{array}{l}\text { C. macroceros (Ehrenberg) } \\
\text { Vanhöffen }\end{array}$ & & $\mathrm{X}$ & M.P.O \\
\hline THALASSIONEMATALES & & & & C. massiliense var. armatum & $X$ & $\mathrm{X}$ & M.P.N \\
\hline THALASSIONEMATACEAE & & & & (Karsten) Jörgensen & & & \\
\hline Thalassionema frauenfeldii & $\mathrm{X}$ & $\mathrm{X}$ & M.P.N-O, Po & C. tripos (O.F. Müller) Nitzsch & $\mathrm{X}$ & $\mathrm{X}$ & M.P.N-O \\
\hline (Grunow) Hallegraeff & & & & C. tripos var. tripos Jörgensen & $\mathrm{X}$ & & M.P.N-O \\
\hline T. nitzschioides (Grunow) & $X$ & $\mathrm{X}$ & M.P.O & GONYAULACACEAE & & & \\
\hline Mereschkowsky & & & & Gonyaulax sp. & $X$ & $X$ & \\
\hline BACILLARIOPHYCEAE & & & & OXYTOXACEAE & & & \\
\hline EUNOTIOPHYCIDAE & & & & Oxytoxum sp. & $\mathrm{X}$ & $\mathrm{X}$ & \\
\hline EUNOTIALES & & & & PERIDINIALES & & & \\
\hline EUNOTIACEAE & & & & PROTOPERIDINIACEAE & & & \\
\hline Eunotia sp. & $X$ & & & Protoperidinium sp. 1 & $\mathrm{X}$ & $\mathrm{X}$ & \\
\hline BACILLARIOPHYCIDAE & & & & Protoperidinium sp. 2 & $\mathrm{X}$ & $\mathrm{X}$ & \\
\hline NAVICULALES & & & & PODOLAMPACEAE & & & \\
\hline DIPLONEIDINEAE & & & & Podolampas sp. & $\mathrm{X}$ & & \\
\hline DIPLONEIDACEAE & & & & PROROCENTRALES & & & \\
\hline Diploneis sp. & $\mathrm{X}$ & $\mathrm{X}$ & & PROROCENTRACEAE & & & \\
\hline NAVICULINEAE & & & & Prorocentrum sp. & & & \\
\hline PLEUROSIGMATACEAE & & & & & & & \\
\hline
\end{tabular}


setembro/2004

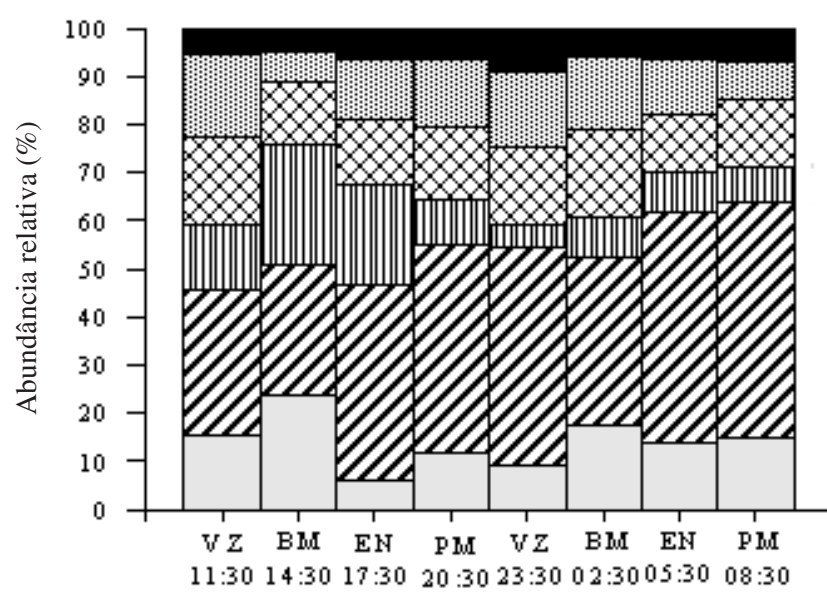

março/2005

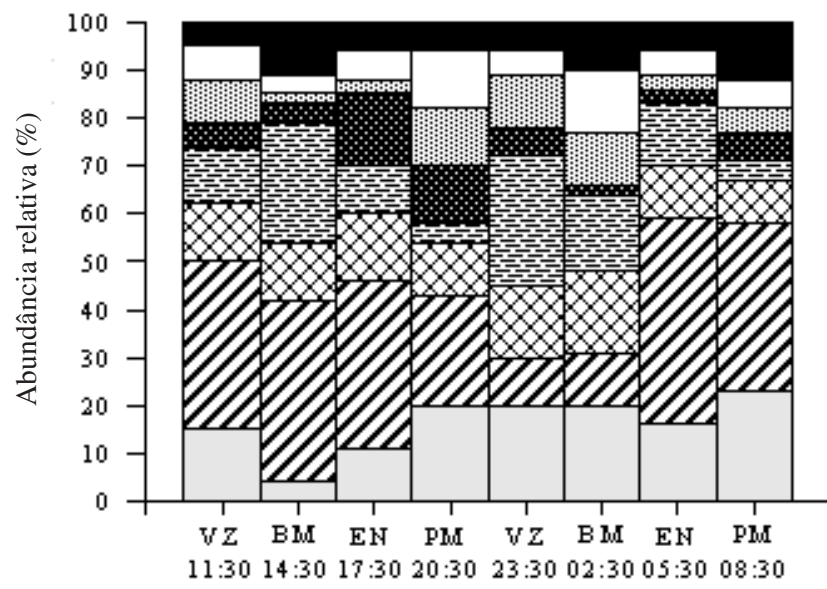

Marés/horas

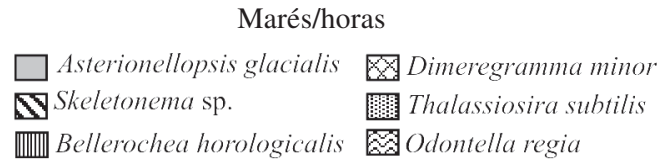

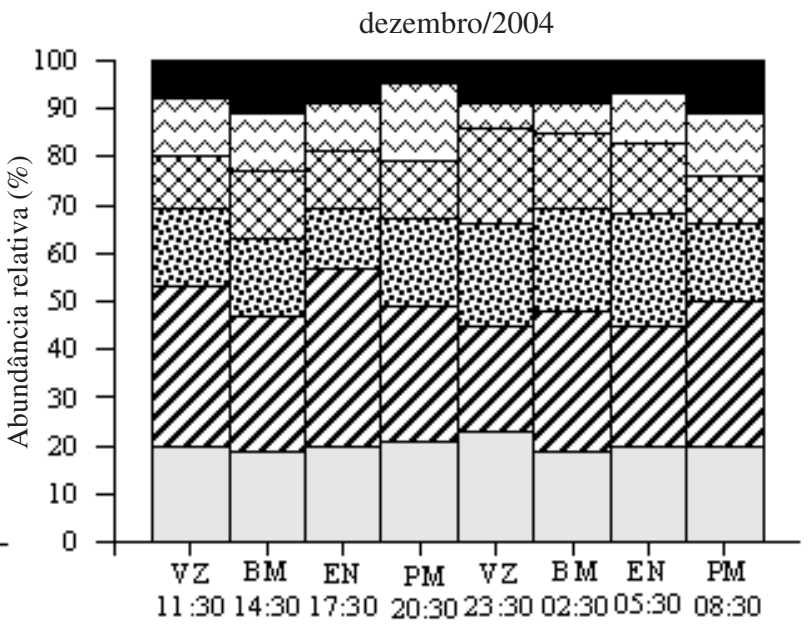

junho/2005

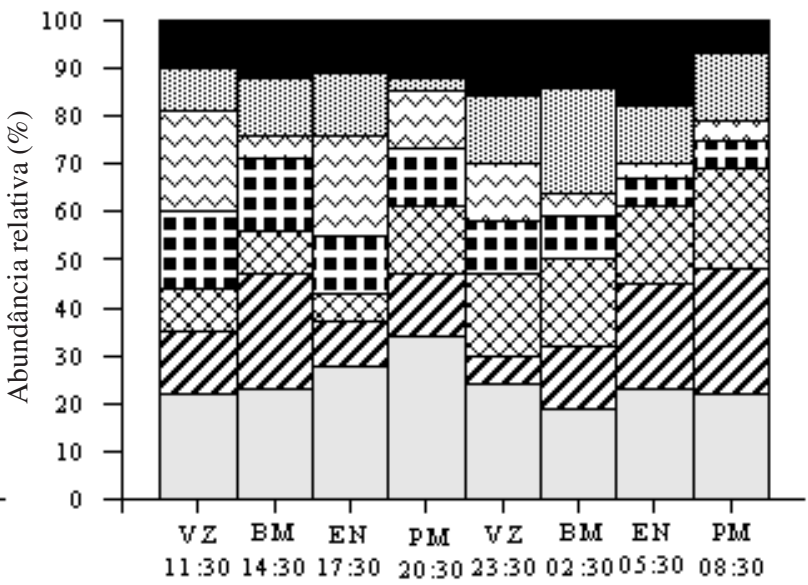

Marés/horas

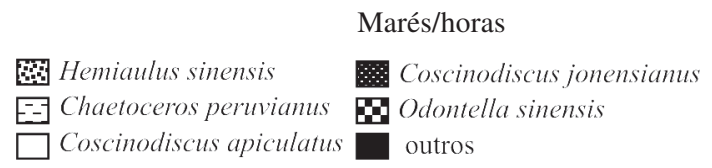

Figura 7. Variação nictemeral da abundância relativa das espécies microfitoplanctônicas durante os períodos seco (setembro e dezembro/2004) e chuvoso (março e junho/2005) da ilha Canela (Bragança, PA, Brasil).

Triceratium biquadratum e Triceratium pentacrinus são referidas pela primeira vez para a costa Norte brasileira. Os dinoflagelados estiveram representados por espécies, predominantemente, neríto-oceânicas comuns em ambientes marinhos costeiros do Nordeste paraense (Soares \& Paiva 2002; Simith et al. 2002). As cianofíceas tiveram pouca representatividade, provavelmente, devido aos altos valores de salinidade registrados na área de estudo.

Em zona de arrebentação, os dinoflagelados encontram-se associados à baixa energia de ondas e a altos valores de intensidade luminosa na coluna da água (Odebrecht \& Garcia 1998), tendo este grupo demonstrado uma baixa representatividade, possivelmente, devido à alta dinâmica do ambiente estudado.
As diatomáceas estão freqüentemente associadas a regiões de frentes oceânicas e a regiões com elevado estresse caracterizado por uma coluna d'água não estratificada, turbulenta e sob efeito de correntes de alta velocidade (Reynolds 1997; Tilstone et al. 2000; Smayda 2002). Constituem o grupo mais representativo e abundante em águas costeiras (Gin et al. 2000; Huang et al. 2004) e representam os principais produtores primários da zona de arrebentação de praias arenosas (Brown \& McLachlan 1990; Talbot et al. 1990). Sua riqueza taxonômica tem sido referida na maioria dos ambientes costeiros amazônicos, bem como em águas oceânicas e costeiras sob influência do rio Amazonas (Wood 1966; Teixeira \& Tundisi 1967; M. Souza, dados não publicados). No Nordeste paraense encontram-se 
bem representadas na zona costeira bragantina (Soares \& Paiva 2002) e na baía do Caeté (Simith et al. 2002).

As diatomáceas cêntricas foram as principais constituintes do microfitoplâncton das águas costeiras da ilha Canela, sendo o gênero Chaetoceros Ehrenberg o mais numeroso taxonomicamente. Resultados similares foram obtidos na plataforma amazônica (Wood 1966; M. Souza; R. Paiva, dados não publicados) e no estuário do rio Marapanim, Pará (D. Santana, dados não publicados). Este gênero tem sido citado como um dos mais representativos de águas costeiras brasileiras, contribuindo para a alta produtividade e biomassa algal destes ambientes (Passavante \& Feitosa 2004; Moreira Filho et al. 1990), devido a sua alta taxa de crescimento associada à águas muito turbulentas (Smetacek 1988).

Os meses de setembro e dezembro (período seco) apresentaram o maior número de táxons identificados (109 e 115 táxons, respectivamente). Além da presença de células do fitoplâncton, os organismos do fitobentos foram bastante representativos. Os ventos mais intensos durante os meses de setembro e dezembro (velocidade média $=3,8 \mathrm{~m} \cdot \mathrm{s}^{-1}$ e $3,5 \mathrm{~m} \cdot \mathrm{s}^{-1}$, respectivamente) contribuíram para o aumento do número destes organismos na superfície da água, através do processo de ressuspensão do sedimento e do empilhamento de células microalgais.

As espécies abundantes e muito freqüentes na área de estudo foram Asterionellopsis glacialis, Dimeregramma minor, Skeletonema sp. e Thalassiosira subtilis, sendo esta última uma espécie oceânica citada, para a costa Norte brasileira, apenas nos estudos de Müller-Melchers (1957) realizados na costa paraense.

A. glacialis, uma espécie eurialina adaptada a ambientes costeiros turbulentos, esteve presente em todos os meses de coleta. Odebrecht et al. (2003) registraram na praia do Cassino (RS) altas concentrações de clorofila $a$ relacionadas às grandes densidade deste organismo, o qual representa uma importante fonte de carbono para a cadeia trófica da região (Garcia \& Gianuca 1997). Desta forma, este organismo, possivelmente, exerce semelhante papel na área estudada.

O gênero Skeletonema apresenta organismos neríticos $k$-estrategistas, fato associado à presença de águas turbulentas (Smetacek 1986), como as observadas na ilha Canela. Bem representados ao longo do período de estudo, os organismos deste gênero não foram identificados ao nível específico. Embora seja comum o registro de $S$. costatum nas costas do Norte e Nordeste brasileiras (Simith et al. 2002; Soares \& Paiva 2002; Moreira Filho et al. 1999), dados moleculares obtidos a partir de organismos deste gênero coletados em estuários amazônicos discutem a ocorrência desta espécie na costa Norte do Brasil (Bandeira, dados não publicados).
D. minor, espécie marinha litoral ticoplanctônica que constitui comunidades bentônicas sobre a superfície de sedimentos de mangue (Hassan et al. 2006) e sedimentos arenosos (Cook \& Roy 2006), esteve bem representada no ambiente em estudo. Sua presença se deve, possivelmente, à pequena profundidade no entorno da ilha Canela, a qual sofre a ação de ventos, correntes de marés e litorâneas e de ondas que, em conjunto, permitem uma maior homogeneização da coluna d'água e ressuspensão dos sedimentos, nutrientes e organismos epipsâmicos (Losada et al. 2000; Odebrecht et al. 2003).

Aparentemente, o padrão de distribuição temporal nas águas costeira da ilha Canela não foi caracterizado por alterações na estrutura de toda a comunidade fitoplanctônica, mas sim, de certas populações, como as das espécies referidas anteriormente, as quais são mais suscetíveis às flutuações de determinados fatores ambientais, embora as mesmas estejam presentes ao longo de todo o ciclo sazonal. Resultados similares foram observados por Lacerda et al. (2004), para o estuário do rio Botafogo (PE) e Santander et al. (2003), em águas oceânicas e costeiras do Norte do Chile.

As condições hidrológicas características da zona de arrebentação da ilha Canela proporcionaram a dominância de espécies marinhas planctônicas neríticas, além da presença de um elevado número de espécies litorais ticoplanctônicas e mesclas de organismos, eurialinos, mesoalóbios e, principalmente, polialóbios, uma vez que a salinidade apresentou valores elevados durante todos os meses de estudo, embora tenha apresentado uma variação sazonal definida. O domínio de espécies neríticas foi igualmente referido por diversos autores para ambientes costeiros do Nordeste brasileiro, tais como o estuário do rio Goiana, PE (Feitosa et al. 1999) e da baía de Tamandaré, PE (Rosevel da Silva 2005), em estuários, baías, manguezais e praias do sul do País: PR, SC e RS (Moreira Filho et al. 1990). Não obstante, nestes ambientes, em função das oscilações de salinidade, prevaleceram às espécies eurialinas.

$\mathrm{Na}$ ilha Canela, a riqueza taxonômica, aparentemente, não esteve diretamente relacionada aos diferentes períodos sazonais e aos ciclos de marés estudados. Não obstante, foi possível observar o efeito da salinidade sobre a composição florística local, a qual, durante o período seco, esteve representada por alguns organismos oceânicos não registrados durante o período chuvoso. Outros fatores como os movimentos de marés, a ação dos ventos e as correntes marinhas litorâneas, são sugeridos como fatores que condicionaram a dinâmica de algumas populações de microalgas consideradas muito freqüientes e abundantes na área de estudo, principalmente, a espécie ticoplanctônica D. minor. 


\section{Agradecimentos}

Os autores agradecem à Coordenadoria de Aperfeiçoamento de Pessoal de Nível Superior (CAPES), pela concessão da bolsa de Mestrado à primeira Autora; ao Conselho Nacional de Desenvolvimento Científico Tecnológico ( $\mathrm{CNPq}$ ), pelas bolsas de pesquisa concedidas aos autores Luci Carneiro Cajueiro Pereira (\#304392/2005-7) e Rauquírio Marinho da Costa (\#308953/2006-1).

\section{Referências bibliográficas}

Almeida, I.C.S.; Ferreira-Correia, M.M. \& Dourado, E.C.S..S. 2004 Microalgas da Baía de Turiaçu, APA das Reentrâncias Maranhensesuma abordagem qualitativa. Boletim do Laboratório de Hidrobiologia 17: 1-19.

Brandini, F.P.; Lopes, M.R.; Gutseit, S.K.; Spach, L.H. \& Sassi, R. 1997. Planctologia na Plataforma Continental do Brasildiagnose e revisão bibliográfica. Rio de Janeiro, Fundação de Estudos do Mar (FEEMAR).

Brown, A.C. \& McLachlan, A. 1990. Beach and surf-zone flora. Ecology Sandy Shores 5: 41-55.

Cook, P.M.L \& Roy, H. 2006. Advective relief of $\mathrm{CO}_{2}$ limitation in microphytobenthos in highly productive sandy sediments. Limnology and Oceanography 51: 1594-1601.

Desikachary, T.S. 1959. Cyanophyta. New Delhi, Council of Agricultura Researcer.

Feitosa, F.A.N.; Silva-Cunha, M.G.G.; Passavante, J.Z.O.; NeumannLeitão, S. \& Lins, I.C. 1999. Estrutura do microfitoplâncton no sistema estuarino do rio Goiana, Pernambuco, Brasil. Trabalhos Oceanográficos da Universidade Federal de Pernambuco 27: $15-25$.

Garcia, V.M.T \& Gianuca, N.M. 1997. The beach and surfzone. Pp. 166-170. In: U. Seeliger; C. Odebrecht \& J.P. Castello (eds.). Subtropical Convergence Environments: The Coast and Sea in the Southwestern Atlantic. New York, Springer-Verlag.

Gin, K.Y.H., Lin, X. \& Zhang, S. 2000. Dynamics and size structure of phytoplankton in the coastal waters of Singapore. Journal Plankton Research 22: 1465-1484.

Hassan, G.S.; Espinosa, M.A. \& Islã, F.I. 2006. Modern diatom assemblages in surface sediments from estuarine systems in the southeastern Buenos Aires Province, Argentina. Journal of Paleolimnology 35: 39-53

Huang, L.; Jian, W.; Song, X.; Huang, X.; Liu, S.; Qian, P.; Yin, K. \& Wu, M. 2004. Species diversity and distribution for phytoplankton of the Pearl river estuary during rainy and dry seasons. Marine Pollution Bulletin 49: 88-596.

Isaac, V.J. \& Barthem, R.B. 1995. Os Recursos pesqueiros da Amazônia brasileira. Belém, PR-MCT/CNPq/Museu Paraense Emílio Goeldi.

Kjerfve, B. \& Lacerda, L.D. 1993. Mangroves of Brazil. Pp. 245-272. In: L.D. Lacerda (ed.). Mangrove ecosystems technical reports. ITTO TS-13, 2 .

Lacerda, S.R.; Koening, M.L.; Neumann-Leitão, S. \& Flores-Montes, M.J. 2004. Phytoplankton nyctemeral variation at a tropical river estuary (Itamaracá-Pernambuco-Brazil). Brazilian Journal Biology 64: 81-94.

Lara, R.J. 2003. Amazonian mangroves-a multidisciplinary case study in Pará State, North Brazil: introduction. Wetlands Ecology and Management 11: 217- 221.

Lobo, E. \& Leighton, G. 1986. Estructuras comunitarias de las fitocenosis planctónicas de los sistemas de desembocaduras de rios y esteros de la zona central de Chile. Revista Biología Marina 22:1-29.
Losada, A.P.M.; Feitosa, F.A.N.; Correia-Lins, I. 2000. Variação sazonal e espacial da biomassa fitoplanctônica nos estuários dos Rios Ilhetas e Mamucaba (Tamandaré-PE) relacionada com parâmetros hidrológicos. Trabalhos Oceanográficos da Universidade Federal de Pernambuco 28: 117-138.

Magalhães, A.L.P.; Costa, R.A.A.M.; Pereira, L.C.C.; Liang, T. \& Ribeiro, M.J.S. 2006. Spatial and temporal distribution in density and biomass of two Pseudodiaptomus species (Copepoda: Calanoida) in the Caeté river estuary (Amazon region - North of Brazil). Brazilian Journal of Biology 66: 421-430.

Mateucci, S.D. \& Colma, A. 1982. Metodología para el estudo de la vegetación. Collecion de Monografías Científicas, Série Biologia.Washington, Secretaria General de la Organizacón de los Estados Americanos.

Martorano, L.G.; Perreira, L.C.; César, E.G.M. \& Pereira, I.C.B. 1993. Estudos climáticos do Estado do Pará, classificação climática (Köppen) e deficiência hídrica (Thornthwhite Mather). Belém, SUDAM/EMBRAPA, SNLCS.

Melo, N.F.A.C.; Paiva, R.S. \& Silva, M.M.T. 2006. Variação diurna da densidade planctônica na região intertidal da praia de Ajuruteua (Bragança-Pará). Boletim do Museu Paraense Emílio Goeldi, Série Ciências Naturais 1: 153-180.

Moraes, B.C.; Costa, J.M.N; Costa, A.C.L. \& Costa, M.H. 2005. Variação espacial e temporal da precipitação no Estado do Pará. Acta Amazonica 35: 207-214.

Moreira Filho, H.; Eskinazi-Leça, E.; Valente-Moreira, I.M. \& Cunha, J.A. 1999. Avaliação taxonômica e ecológica das diatomáceas (Chrysophyta-Bacillariophyceae) marinhas e estuarinas nos Estados de Pernambuco, Paraíba, Rio Grande do Norte, Ceará, Piauí, Maranhão, Pará e Amapá, Brasil. Trabalhos Oceanográficos da Universidade Federal de Pernambuco 27: 55-90.

Moreira Filho, H.; Valente-Moreira, I.M.; Souza-Mosimann, R.M. \& Cunha, J.A. 1990. Avaliação florística e ecológica das diatomáceas (Chrysophyta, Bacillariophyceae) marinhas e estuarinas nos Estados do Paraná, Santa Catarina e Rio Grande do Sul. Estudos de Biologia 25: 5-48.

Müller-Melchers, F.C. \& Ferrando, H. 1956. Técnicas para el estudio de las diatomeas. Boletim Instituto Oceanográfico 7: 151-160.

Müller-Melchers, F.C. 1957. Plankton diatoms of the Toko-Maru voyage (Brazil Coast). Boletim do Instituto Oceanográfico 7: 111-136.

Odebrecht, C \& Garcia, V.M.T. 1998. Phytoplankton. Pp. 105-109. In: U. Seeliger; C. Odebrecht \& J.P. Castello (eds.). Subtropical Convergence Environments. New York, Springer-Verlag.

Odebrecht, C.; Abreu, P.C.; Fugita, C.C. \& Bergesch, M. 2003. The impact of mud deposition on the long term variability of the surfzone diatom Asterionellopsis glacialis (Castracane) Round at Cassino Beach, Brazil. Journal of Coastal Research 35: 486-491.

Passavante, J.Z.O. \& Feitosa, F.A.N. 2004. Dinâmica da produtividade fitoplanctônica na zona costeira marinha. Pp. 425-439. In: E. Eskinazi-Leça; S. Neumann-Leitão \& F. Costa (eds.). Oceanografia: um cenário tropical. Recife, Edições Bagaço.

Reynolds, C.S. 1997. Vegetation processes in the pelagic: a model for ecosystem theory. Pp. 223-247. In: O. Kinne (ed.). Excellence in Ecology. Oldendorf, Ecology Institute Publisher.

Rosevel da Silva, M.; Silva-Cunha, M.da.G.G.; Feitosa, F.A.N. \& Muniz, K. 2005. Estrutura da comunidade fitoplânctônica na baía de Tamandaré (Pernambuco, Nordeste do Brasil). Tropical Oceanography 33: 159-177.

Round, F.E.; Crawford, R.M. \& Mann, D.G. 1990. The diatoms: biology and morphology of the genera. New York, Cambrigde Universit Press.

Santander, E.; Herrera, L. \& Merino, C. 2003. Fluctuación diaria del fitoplancton em la capa superficial del océano durante la primavera de 1997 en el Norte de Chile (20¹8’S): II. Composición específica y abundância celular. Revista Biología Marina y Oceanografia 38: $13-25$.

Schories, D. \& Gorayeb, I. 2001. CD-1: A Biodiversidade e a comunidade de pescadores na ilha Canela. Belém, MCT/ Museu Paraense Emílio Goeldi. 
Silva-Cunha, M.G.G. \& Eskinazi-Leça, E. 1990. Catálogo das diatomáceas (Bacillariophyceae) da Plataforma Continental de Pernambuco. Recife, SUDENE.

Simith, D.J.B.; Costa, R.M.; Pereira, L.C.C \& Schories, D. 2002. Composição florística e abundância do fitoplâncton da baía do estuário do rio Caeté (Bragança- Pará-Brasil). CD-ROM. In: Anais IV Workshop ECOLAB - Ecossistemas Costeiros Amazônicos do Conhecimento à Gestão. Belém.

Sistema de Veneza. 1958. Symposium on the classification of brackish waters. Archives Limnology and Oceanography 11: 1-248.

Smayda, T.J. 2002. Turbulence, watermass stratification and harmful algal bloms: an alternative view and frontal zones as "pelagic seed banks". Harmful Algae 1: 95-112.

Smetacek, V.S. 1986. Impacto of freshwater discharge on production and transfer of materials in the marine eviroment. Pp: 45-51. In: S. Skreslet (ed.). The Role of freshwater Outflow in Coastal Marine Ecosystems. Berlin, Nato Asi séries.

Smetacek, V.S. 1988. Plankton characteristics. Pp. 93-130. In: H. Postma \& J.J. Zijlstra (eds.). Ecosystems of the wold: Continental Shelvers. Amsterdam, Elsevier.

Smith, W.O. Jr. \& Demaster, D.J. 1996. Phytoplankton and biomass productivity in the Amazon river plume: correlation with seasonal river discharge. Continental Shelf Research 16: 291-317.

Soares, C \& Paiva, R. 2002. Atlas do fitoplâncton do estuário do rio Caeté e da Zona Costeira Bragantina (Bragança-Pará). CD-ROM. In: Anais do IV Workshop ECOLAB - Ecossistemas Costeiros Amazônicos do Conhecimento à Gestão. Belém.

Sournia, A. 1986. Atlas du phytoplancton marin. Paris, Editions du Centre National de la Recherche Scientifique.

Souza Filho, P.W.M. \& El-Robrini, M. 1996. Morfologia, processos de sedimentação e litofácies dos ambientes morfosedimentares da Planície Costeira Bragantina - Nordeste do Pará (Brasil). Geonomos 4: 1-16.
Steindinger, K.A. \& Tangen, K. 1997. Dinoflagellates. Pp. 387-598. In: C.R. Tomas (ed.). Identifying marine diatoms and dinoflagelates. San Diego, Academic Press.

Talbot, M.M.B.; Bate, G.C. \& Campbell, E.E. 1990. A review of the ecology of the surf zone diatoms, with special reference to Anaulus australis. Oceanography and Marine Biology. An Annual Review 28: 155-175.

Teixeira, C. \& Tundisi, J.G. 1967. Primary production and phytoplankton in equatorial waters. Bulletin of Marine Science 17: 884-891.

Tilstone, G.H.; Míguez, B.M.; Figueiras, F.G. \& Fermín, E.G. 2000. Diatom dynamics in a coastal ecosystem affected by upwelling: coupling between species succession, circulation and biogeochemical processes. Marine Ecology Progress Series 205: 23-41.

Tomas, C.R. 1997. Identifying marine phytoplankton. San Diego, Academic Press.

Valente-Moreira, I.M.; Moreira Filho, H.; Cunha, J.A. \& Shirata, M.T. 1987. A Flórula diatomológica marinha e estuarina nos balneários de Canoas e Ipanema, Estados do Paraná, Brasil (ChrysophytaBacillariophycea). Estudos de Biologia 17: 24-48.

Valente-Moreira, I.M.; Moreira Filho, H. \& Cunha, J.A. 1994. Diatomáceas (Chrysophyta, Bacillariophyceae) em biótopo de manguezal do rio Perequê, em Pontal do Sul, Paranaguá, Estado do Paraná, Brasil. Acta Biológica Paranaense 23: 55-72.

Valiela, I. 1995. Marine ecological processes. New York, SpringerVerlag.

Vannucci, M. \& Quieroz, D. 1963. Plâncton coletado durante a viagem VII do N/E "Almirante Saldanha": Relatório Técnico. Contribuição Avulsa do Instituto Oceanográfico 4: $1-25$.

Wood, E.J.F. 1966. A phytoplankton study of the Amazon region. Bulletin of Marine Science 16: 102-123. 